\title{
A Sustainable world with cartography
}

\section{Ayako Kagawa $^{1}$, Kyoung-Soo Eom ${ }^{2}$}

Authors are officers at the Geospatial Information Section (formerly Cartographic Section), Department of Field Support, United Nations, New York, United States of America; kagawa@un.org, eom@un.org

The views expressed are those of the author(s) and do not necessarily reflect those of the United Nations. (ST/Al/189/Add.6/Rev.5)

Keywords: United Nations, Sustainable Development Goals, Maps, Cartographers, Geospatial Information, Geospatial Information Management experts, communication

\begin{abstract}
:
The 2030 Agenda for Sustainable Development or also known as the Sustainable Development Goals (SDGs) is the new global paradigm and blueprint to achieve a better and more sustainable future for all. To collectively achieve the SDGs, the global community agreed on 17 Goals as a baseline framework to measure and monitor its growth. How to measure and monitor development progress by countries has been a long-standing debate since the era of Millennium Development Goals (MDGs) in the 2000s but with the establishment of Inter-Agency and Expert Group on SDG Indicators (IAEG-SDGs), the SDGs have a clearer framework on how to monitor progress and the global community are grappling on how to effectively collect, analyse, visualise and report their successes.
\end{abstract}

Within the United Nations, there is the desire to elaborate collectively principles and tools on how best to report the SDGs at country and local level as its success lies in the ownership and accountability at all levels. The SecretaryGeneral of the United Nations is looking into how technologies can accelerate the SDGs and to facilitate the alignments with the values enshrined in the United Nations Charter, the Universal Declaration of Human Rights, and the norms and standards of International Laws.

In this paradigm, what should be the role of cartographers and geospatial information management experts to ensure how maps and geospatial information can be effectively used by the global community to communicate their challenges and successes from planning to implementing, monitoring, analysing, visualising and reporting on sustainable development? This paper argues the importance of understanding the challenges, asking questions to the policy makers, sharing best practices and building a consensus on the issues surrounding the SDGs before demonstrating the diverse cartographic skills available to design and communicate the intended message better. Hence, the importance of context has never changed and provides the cartographic and geospatial information management community an opportunity to demonstrate the potential and to provide effective support through cartography for the accomplishment of the sustainable development agenda. 